\title{
Antioxidative Potential and Phytochemical Content of Detox Water
}

\author{
Ganguli P. Ariyawansa and Rahini Ramanathan*
}

School of Applied Sciences, Faculty of Engineering, Science and Technology, Nilai University, 71800 Nilai, Negeri Sembilan, Malaysia.

\section{* Corresponding Author email: rahinivelayutham.rv@gmail.com}

Article History

Received: 11 June 2021

Accepted: 31 July 2021

Published: 31 July 2021

Student(s)

- $\quad$ Ganguli P. Ariyawansa

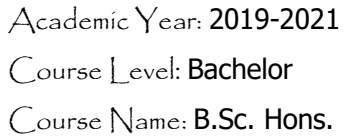

$\operatorname{Mentor}(s)$

- Dr. Rahini Ramanathan

\section{ABSTRACT}

Detox water is a fusion of different fruits immersed in water. It has been shown to possess many health benefits including toxin removal, increased immune function, weight loss and hydration. The following research aimed to extend previous investigation into the beneficial properties of detox water by determining the antioxidant potential and phytochemical content of water infused with a combination of Valencia orange (Citrus sinensis) and Fuji apple (Malus domestica) in different ratios. The three trails studied were 25:75 $\left(\mathrm{T}_{1}\right), 50: 50\left(\mathrm{~T}_{2}\right)$ and 75:25 $\left(\mathrm{T}_{3}\right)$ Apple: Orange ratios. The antioxidant activity, total phenolic content (TPC) and total flavonoid content (TFC) were assayed using the 1, 1-diphenyl-2picrylhydrazyl- DPPH assay, the Folin Ciocalteu assay and the aluminum chloride colorimetric assay respectively. The assays were carried out on water samples taken at $0.5,1,2,4,6$ and 8 hours after infusion, and on the fruit residue. Vitamin $\mathrm{C}$ concentration of the water and fruit residue were determined by titration against potassium iodide at the eight- hour of infusion. The antioxidant, TPC and TFC values of water samples increased with infusion time. At the eight-hour, the antioxidant potential of the water samples ranged from $74.45 \%\left(T_{1}\right)-68.16 \%\left(T_{3}\right)$. The TPC, TFC and Vitamin $\mathrm{C}$ values for all three trails were found to be significantly different $(\mathrm{p}<0.05)$, with TPC values of $189.01 \mu \mathrm{g}$ GAE/ml sample $\left(T_{1}\right), 172.10 \mu \mathrm{g}$ GAE/ml sample $\left(T_{2}\right)$ and 144.82 $\mu \mathrm{g} \mathrm{GAE} / \mathrm{ml}$ sample $\left(\mathrm{T}_{3}\right)$; TFC values were $32.11 \mu \mathrm{g} \mathrm{QE} / \mathrm{ml}$ sample $\left(\mathrm{T}_{1}\right), 25.24 \mu \mathrm{g} \mathrm{QE} / \mathrm{ml}$ sample $\left(\mathrm{T}_{2}\right)$ and $17.62 \mu \mathrm{g} \mathrm{QE} / \mathrm{ml}$ sample $\left(T_{3}\right)$. Vitamin $C$ values were $237.76 \mu \mathrm{g}$ vitamin $\mathrm{C} / \mathrm{ml}$ sample $\left(\mathrm{T}_{1}\right), 161.44 \mu \mathrm{g}$ vitamin $\mathrm{C} / \mathrm{ml}$ sample $\left(\mathrm{T}_{2}\right)$ and $114.48 \mu \mathrm{g}$ vitamin $\mathrm{C} / \mathrm{ml}$ sample $\left(\mathrm{T}_{3}\right)$. The fruit residues possessed very low antioxidant potential and phytochemical content. The study has proven that detox water possesses beneficial properties due to its high phytochemical content.

Keywords: Detox water, Total Phenolic Content, Total Flavonoid Content. 


\section{Introduction}

Detox water is water that has been infused with the flavours of fresh fruits (lemon, kiwi, watermelon, apple), vegetables (carrots, cucumbers, beetroot), or herbs (mint, sage, basil). It is also known as fruit-infused water or fruit-flavored water. It is made by infusing flavour, rather than juicing and so contains very few calories. As such, detox water is also often recommended in weight loss plans, especially in place of high-sugar drinks like sugary soda and fruit juice [1].

The human body is composed of two thirds water and water is known to be essential for cellular function [2]). As such it is important to replenish the water that is lost in daily activities. Pure water is tasteless and lacks flavour, thus many people find it much easier to drink more water throughout the day when it tastes like infused fruit. The benefits of water include weight loss, healthier skin, regular bowel movement, lubricates muscles, alleviates fatigue, improves brain function, regulates body temperature and improves the immune system [3].

Consumption of fruits and vegetables have been shown to increase life span [4], improve mental [5] and cardiovascular health, prevent cancer [6] and help in weight management $[7,8]$ among other ailments. It has been shown that fruits, vegetables, and herbs consist of various bioactive compounds like flavonoids (quercetin and kaempferol), phenolic acids (chlorogenic acid and caffeic acid), and carotenoids (lutein and zeaxanthin), as well as vitamins, minerals and fibers [9].

These bioactive compounds have proven to exert beneficial effects on human health by preventing diseases caused by oxidative stress. Oxidative stress releases free oxygen radicals in the body and has been implicated in several disorders including cancer, auto-immune disease and ageing. These phytochemicals act as antioxidants by scavenging free radicals [10]. The phytochemicals can be released from the plant materials by immersing into water. This method is known as water infusion [11]. Alternatively, it is a way to consume fruits with the intention of receiving the same health benefits and nutrition of the original fruit [12].

Even though the antioxidant properties of fruit have been well documented, few studies have been conducted to evaluate the antioxidant properties and phytochemical content of fruit infused water. An earlier study by the authors had shown that water infused individually with apples and oranges possess antioxidant potential due to the phenolic content in the water. This study was undertaken as an extension to investigate the antioxidant and phytochemical composition of water infused with various combinations of apple: orange.

\section{Research Methodology}

\subsection{Preparation of fruit infused water}

\subsubsection{Collection and preparation of fruits}

The fruits: Valencia orange (Citrus sinensis 'Valencia') and Fuji apple (Malus domestica) were purchased from supermarkets in Nilai, Negeri Sembilan. The fruits were washed under running water and then rinsed with distilled water at room temperature $\left(25 \pm 1{ }^{\circ} \mathrm{C}\right)$ for thirty seconds, to remove any contaminants that might be present on the peels. The fruits were then patted dry with a clean towel to remove excess water. A mandoline slicer was used to cut the fruits into uniform slices.

\subsubsection{Preparation of samples}

The apple and orange slices with peel were combined in three different w/w ratios: $25: 75\left(\mathrm{~T}_{1}\right), 50: 50\left(\mathrm{~T}_{2}\right)$ and 75:25 ( $\left.\mathrm{T}_{3}\right)$ (Apple: Orange) and placed inside $900 \mathrm{ml}$ glass bottles. The bottles were filled with distilled water. The fruits were immersed in water in 1:3 (weight: volume) ratio. The bottles were then closed firmly and left for 8 hours at room temperature $\left(25 \pm 1^{\circ} \mathrm{C}\right)[13]$. 


\subsection{Assays}

\subsubsection{DPPH assay}

The DPPH (1, 1-diphenyl-2-picrylhydrazyl) free radical scavenging activity was determined by the method described by Sridhar and Charles, [14]. An aliquot of $0.70 \mathrm{ml}$ of fruit infused water (sample) was taken at time intervals of 30 minutes, $1,2,4,6$, and 8 hours after infusion. Next, $0.70 \mathrm{ml}$ of $(100 \mu \mathrm{M})$ DPPH methanolic solution was added to $0.70 \mathrm{ml}$ of sample and mixed. The mixture was then incubated for 20 minutes at room temperature $\left(25 \pm 1{ }^{\circ} \mathrm{C}\right)$ in the dark. A UV/Vis spectrophotometer (Secomam Prim, RS232) was used to measure the absorbance at $515 \mathrm{~nm}$. The absorbance was measured against a blank of distilled water. Ascorbic acid $(1 \mathrm{mg} / \mathrm{ml})$ was used as the positive control. The absorbance of all samples, carried out in triplicates, was recorded.

The scavenging effect of DPPH radical was calculated using the following equation:

$$
\text { DPPH scavenging effect }(\%)=\frac{\text { A control-A sample }}{A \text { control }} \times 100
$$

\subsubsection{Total phenolic content (TPC) assay}

To determine the total phenolic content (TPC), the methodology of Arruda et al., [15] was used with slight modifications. An aliquot of $0.10 \mathrm{ml}(100 \mu \mathrm{l})$ of fruit infused water was taken at time intervals of 30 minutes, 1,2,4,6 and 8 hours after infusion. The TPC content of the fruit infused water was determined using the Folin-Ciocalteu method. Briefly, $0.10 \mathrm{ml}(100 \mu \mathrm{l})$ of infused water sample was mixed with $100 \mu \mathrm{l}$ of FolinCiocalteu reagent $(50 \% \mathrm{v} / \mathrm{v})$ and $800 \mu \mathrm{l}$ of sodium carbonate $(5 \% \mathrm{~m} / \mathrm{v})$. The solution was mixed and then incubated for $20 \mathrm{~min}$ at $40{ }^{\circ} \mathrm{C}$ in a water bath (J-Lab Tech, LWB-1220). The absorbance was measured at $760 \mathrm{~nm}$ against a blank by using a UV/Vis spectrophotometer (Secomam Prim, RS232). The blank was prepared by replacing the sample with distilled water. Gallic acid in the concentration range of $0.5-8 \mu \mathrm{g} / \mathrm{mL}$ was used for to plot the calibration curve. All samples (except blank) were carried out in triplicates. The total phenolic content of each sample is expressed as $\mu \mathrm{g}$ Gallic Acid Equivalent per ml sample ( $\mu \mathrm{g}$ GAE / $\mathrm{ml}$ sample) [15].

\subsubsection{Total flavonoid content (TFC) assay}

The total flavonoid content (TFC) of the samples was measured based on the method of Kamtekar et al., [16] using the aluminium chloride colorimetric assay. $1 \mathrm{ml}$ of fruit infused water was taken at time intervals of 30 minutes, 1,2,4,6 and 8 hours after infusion. After that, $1 \mathrm{ml}$ of sample was mixed with $4 \mathrm{ml}$ of distilled water and $0.3 \mathrm{ml}$ of sodium nitrite $(5 \% \mathrm{w} / \mathrm{v})$ and incubated at room temperature for 5 minutes. Then, 0.3 $\mathrm{ml}$ of aluminum chloride $(10 \% \mathrm{w} / \mathrm{v})$ was added to the mixture and left at room temperature for 6 minutes. Next, $2 \mathrm{ml}$ of $1 \mathrm{M}$ sodium hydroxide was added and the mixture was topped up with distilled water to a final volume of $10 \mathrm{ml}$. Then, the mixture was vortex mixed and left at room temperature for 15 minutes. After 15 minutes, the absorbance of the reaction mixture was measured using UV-visible spectrophotometer at $510 \mathrm{~nm}$. The blank was prepared by replacing the sample with distilled water. Quercetin $(0.5-50 \mu \mathrm{g} / \mathrm{ml})$ was used as a standard to generate the calibration curve. The total flavonoid content of each sample is expressed as $\mu \mathrm{g}$ Quercetin Equivalent per $\mathrm{ml}$ sample ( $\mu \mathrm{g} \mathrm{QE} / \mathrm{ml}$ sample) [16].

\subsubsection{Determination of Vitamin C concentration}

After 8 hours of infusion, $20 \mathrm{ml}$ of fruit infused water was removed and placed in a $250 \mathrm{ml}$ conical flask. Then, $1 \mathrm{ml}$ of starch indicator solution $(0.5 \% \mathrm{w} / \mathrm{v})$ was added to the sample. The sample was titrated with $0.005 \mathrm{molL}^{-1}$ iodine solution. The endpoint of the titration was identified as the first permanent trace of a light grey colour due to the starch-iodine complex [17]. 
Antioxidative Potential and Phytochemical Content of Detox Water

Vitamin C (ascorbic acid) concentration of each sample was calculated as follows [17]:

Moles iodine reacting $=$ Concentration of iodine solution $\mathrm{x}$ Ave . vol. iodine solution used

Theory of equation of the titration:

ascorbic acid $+\mathrm{I}_{2} \rightarrow 2 \mathrm{I}^{-}+$dehydroascorbic acid

ascorbic acid: $I_{2}=1: 1$

Moles iodine $=$ Moles ascorbic acid in $20 \mathrm{ml}$ of sample

Moles ascorbic acid $/ \mathrm{ml}=($ moles ascorbic acid in $20 \mathrm{ml}) / 20 \mathrm{ml}$

Concentration of ascorbic acid $=($ Moles ascorbic acid $/ \mathrm{ml}$ x Molar mass ascorbic acid x 106) $\mu \mathrm{g} / 1 \mathrm{ml}(3)$

\subsubsection{Determination of antioxidant potential and phytochemical content of fruit residue}

The measurement of antioxidant potential, phenolic content, flavonoid content and vitamin $\mathrm{C}$ concentration of the fruit residue was performed according to the method of Sun et al., [18]. After 8 hours of infusion, the left-over fruits were taken out. The fruits were placed on petri plates and oven (Jeio Tech, Lab companion OF-11E) dried at $60^{\circ} \mathrm{C}$ to remove moisture. The weight of petri plates was measured intermittently until a constant weight was observed. Once a constant weight was observed, the dried samples were powdered using a blender. Ten grams of each powdered sample was put into a conical flask $(250 \mathrm{ml})$. After that, hundred milliliters $(100 \mathrm{ml})$ of $75 \%$ ethanol: water $(4: 1 \mathrm{v} / \mathrm{v})$ solvent was added to each flask. It has been shown that $75 \%$ ethanol: water solvent yields the highest extraction of phytochemicals (Sun et al., 2015). The mixtures were then agitated using an orbital shaker (Protech, 720) for $60 \mathrm{~min}$ in the dark at room temperature $\left(25 \pm 1{ }^{\circ} \mathrm{C}\right)$. To remove the suspended particles, the homogenate was decanted and centrifuged at $3000 \times \mathrm{g}$ for 15 minutes. Aliquots of the supernatant were taken from each centrifuged sample and DPPH, TPC, TFC and Vitamin C assays were carried out as per the methods mentioned above, to determine the antioxidant potential, phenolic content, flavonoid content and vitamin $\mathrm{C}$ concentration (of the fruit residue) respectively. Due to the intensity of colour, the supernatant was diluted 10-fold for DPPH assay and 50-fold for TPC and TFC assays. The endpoint of the titration (of the fruit residue) was identified as the first permanent trace of a light brown colour.

\subsection{Statistical Analysis}

Three replicates were carried out for each sample. Data were expressed as mean \pm standard deviation where $\mathrm{n}=3$. Statistical comparisons were made using paired sample T-test, analysis of variance (ANOVA) and Tukey-Kramer post hoc test. The statistical significance was set up at $\mathrm{p}<0.05$.

\section{Results}

\subsection{Antioxidant potential}

As can be seen from Figure 1 below, the percentage scavenging of all three trials $\left(T_{1}, T_{2}\right.$ and $\left.T_{3}\right)$ increased with infusion time. 25:75 (Apple: Orange) sample showed the highest percentage scavenging, followed by the 50: 50 (Apple: Orange) and 75:25 (Apple: Orange) samples. The percentage scavenging of 25:75 (Apple: Orange) trial increased from $44.74 \%(0.5 \mathrm{~h})$ to $73.67 \%$ (8h) The percentage scavenging of $25: 75,50: 50$ and 75:25 (Apple: Orange) samples were 73.67\%, 70.37\% and 68.16\% respectively, after 8 hours of infusion. 


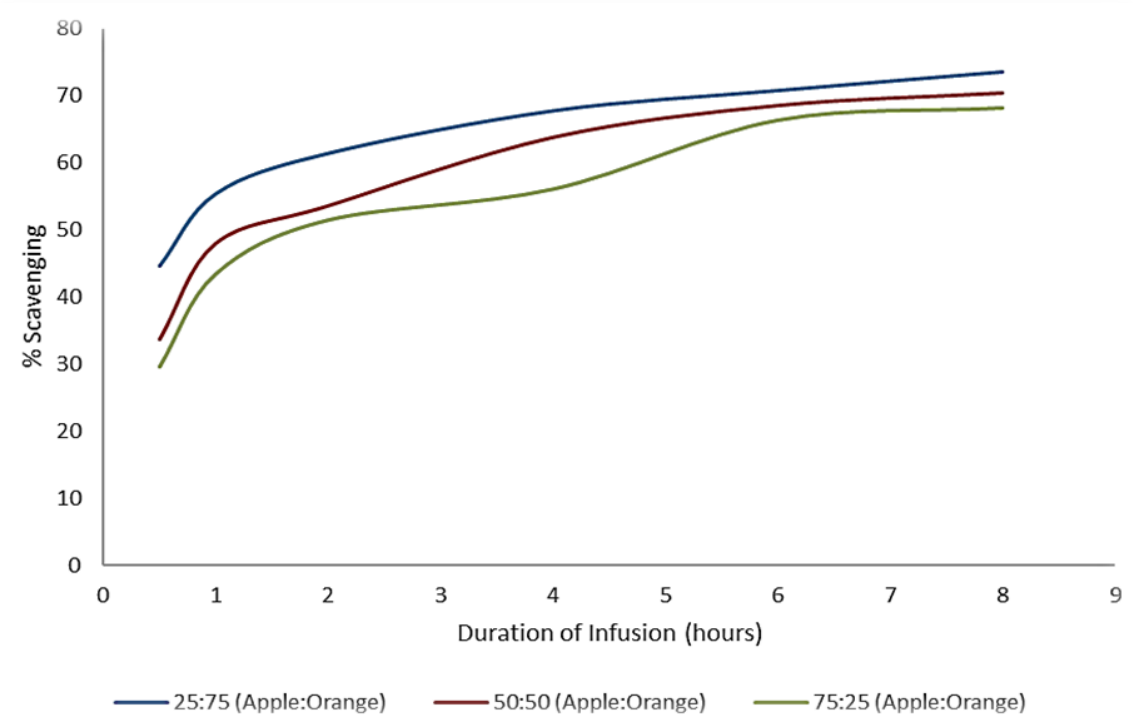

Figure 1: Percentage scavenging of water infused with 25:75, 50:50 and 75:25 (Apple: Orange) trials

Samples were assayed in triplicates $(\mathrm{n}=3)$

$\%$ Scavenging at each time interval was calculated from the average absorbance at $515 \mathrm{~nm}$

\subsection{Total phenolic content}

As shown in Figure 2 below, the total phenolic content of all three trials $\left(T_{1}, T_{2}\right.$ and $\left.T_{3}\right)$ increased with infusion time. 25:75 (Apple: Orange) sample showed the highest total phenolic content, followed by the 50: 50 (Apple: Orange) and 75:25 (Apple: Orange) samples. The total phenolic content of 25:75 (Apple: Orange) sample ranged from $74.72(0.5 \mathrm{~h})$ to 189.03 (8h) $\mu \mathrm{g} \mathrm{GAE} / \mathrm{ml}$ sample. The total phenolic content of 25:75, 50:50 and 75:25 (Apple: Orange) samples were 189.03, 172.08 and $144.80 \mu \mathrm{g} \mathrm{GAE} / \mathrm{ml}$ sample respectively, after 8 hours of infusion.

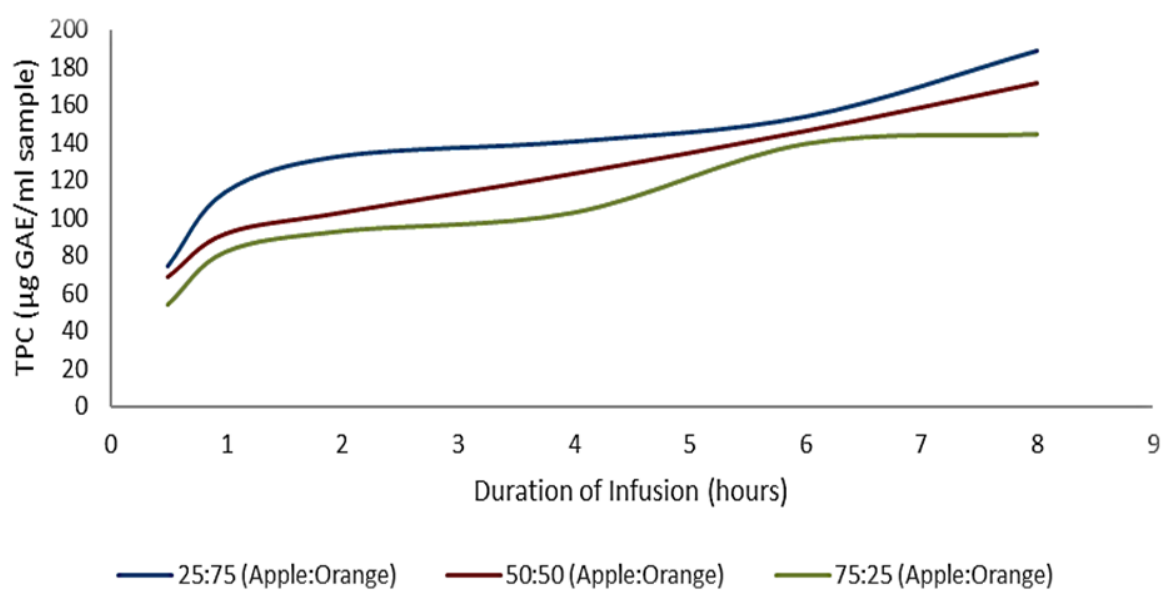

Figure 2: Total phenolic content of water infused with 25:75, 50:50 and 75:25 (Apple: Orange) samples

Phenolic content was calculated using Gallic acid standard curve.

TPC values at each time interval were calculated from the average absorbance readings 


\subsection{Total flavonoid content}

As can be seen from Figure 3, the total flavonoid content of all three trials $\left(T_{1}, T_{2}\right.$ and $\left.T_{3}\right)$ increased with infusion time. 25:75 (Apple: Orange) sample showed the highest total flavonoid content, followed by the 50: 50 (Apple: Orange) and 75:25 (Apple: Orange) trials. The total flavonoid content of 25:75 (Apple: Orange) sample ranged from $14.52(0.5 \mathrm{~h})$ to 32.14 (8h) $\mu \mathrm{g} \mathrm{QE} / \mathrm{ml}$ sample. The total flavonoid content of 25:75, 50:50 and 75:25 (Apple: Orange) samples were 32.14, 25.24 and $17.62 \mu \mathrm{g} \mathrm{QE} / \mathrm{ml}$ sample respectively, after 8 hours.

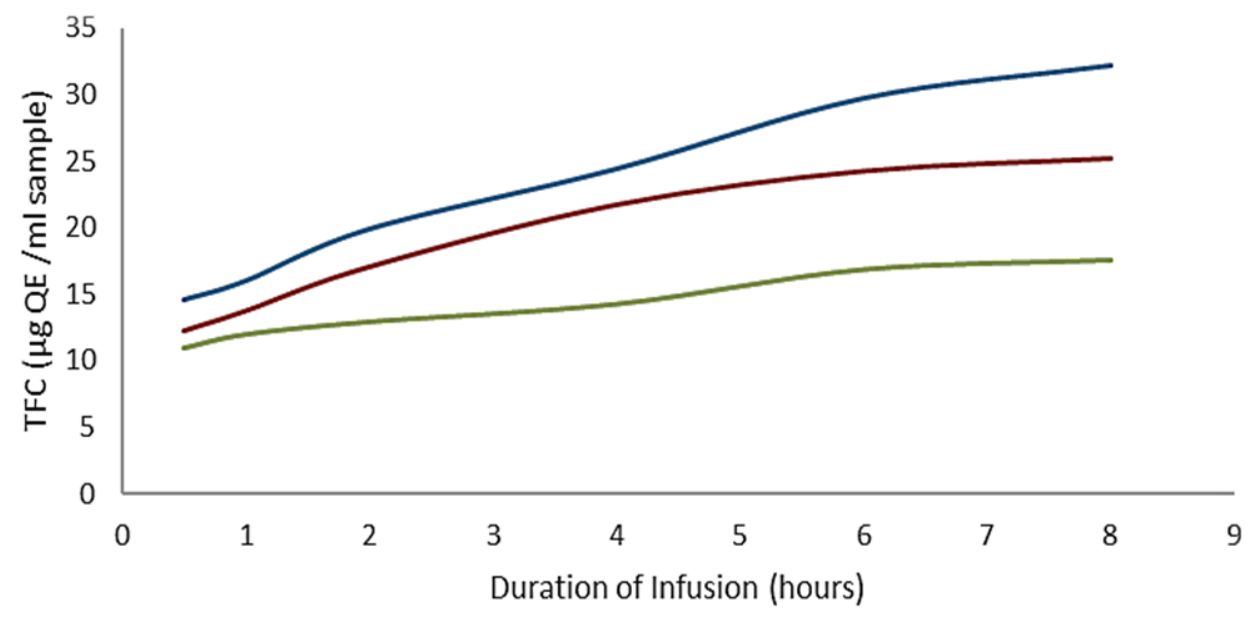

-25:75 (Apple:Orange) — 50:50 (Apple:Orange) — $\quad$ 75:25 (Apple:Orange)

Figure 3: Total flavonoid content of water infused with 25:75, 50:50 and 75:25 (Apple: Orange) samples

*Flavonoid content was calculated using Quercetin standard curve (Appendix Figure C1)

*TFC values at each time interval were calculated from the average absorbance readings.

\subsection{Comparison of \% scavenging and phytochemical content of water infused with Apple: Orange trials at 8 hours}

Table 1 compares percentage scavenging, TPC, TFC and vitamin $\mathrm{C}$ concentration of water infused with "Apple: Orange" samples at 8 hours. At 8 hours, 25:75 (Apple: Orange) sample showed a significantly higher $(\mathrm{p}<0.05)$ percentage scavenging than the 75:25 (Apple: Orange) sample. However, percentage scavenging of 50:50 (Apple: Orange) was comparable to both 25:75 and 75:25 samples as indicated by the same lowercase superscript letters for 25:75 and 50:50 ("a") and 50:50 and 75:25 (b). After 8 hours of infusion, 25:75 (Apple: Orange) sample showed a significantly higher $(\mathrm{p}<0.05)$ TPC, TFC and vitamin C concentration than the other two samples.

Table 1: Comparison of \% scavenging and phytochemical content of water infused with Apple: Orange.

\begin{tabular}{|c|l|c|c|c|}
\hline $\begin{array}{c}\text { Sample } \\
\text { (Apple: Orange) }\end{array}$ & \% Scavenging & $\begin{array}{c}\text { TPC } \\
(\boldsymbol{\mu g G A E} / \mathbf{m l} \\
\text { sample) }\end{array}$ & $\begin{array}{c}\text { TFC ( } \boldsymbol{\mu g Q E} \\
/ \mathbf{m l} \text { sample) }\end{array}$ & $\begin{array}{c}\text { Concentration of } \\
\text { Vitamin C }(\boldsymbol{\mu g} / \mathbf{m l} \\
\text { sample) }\end{array}$ \\
\hline $25: 75\left(\mathrm{~T}_{1}\right)$ & $74.45 \pm 3.44^{\mathrm{a}}$ & $189.01 \pm 1.70^{\mathrm{c}}$ & $32.11 \pm 0.23^{\mathrm{f}}$ & $237.76 \pm 23.30^{\mathrm{i}}$ \\
\hline $50: 50\left(\mathrm{~T}_{2}\right)$ & $70.39 \pm 0.74^{\mathrm{ab}}$ & $172.10 \pm 9.24^{\mathrm{d}}$ & $25.24 \pm 0.24^{\mathrm{g}}$ & $161.44 \pm 17.79^{\mathrm{j}}$ \\
\hline $75: 25\left(\mathrm{~T}_{3}\right)$ & $68.16 \pm 0.96^{\mathrm{b}}$ & $144.82 \pm 2.20^{\mathrm{e}}$ & $17.62 \pm 0.64^{\mathrm{h}}$ & $114.48 \pm 15.87 \mathrm{i}$ \\
\hline
\end{tabular}

Comparison was made for values taken at the eight-hour of infusion.

Statistical comparisons were made using one-way ANOVA followed by Tukey-Kramer post-hoc test $(\mathrm{p}<0.05)$

Letters in superscript indicate significance, comparing the values in the columns. 
Ariyawansa and Ramanathan, Adv. J. Grad. Res.; Vol. 10, Issue 1, pp: 41-50, July 2021

\subsection{Comparison of \% scavenging and phytochemical content of fruit residue}

Table 2 compares the percentage scavenging, TPC, TFC and vitamin $C$ concentration of fruit residue samples at 8 hours. After 8 hours of infusion, the fruit residue of 25:75, 50:50 and 75:25 (Apple: Orange) samples showed similar percentage scavenging and total flavonoid content. In contrast, 25:75 (Apple: Orange) residue sample showed a significantly higher $(\mathrm{p}<0.05)$ TPC and vitamin $\mathrm{C}$ concentration than the other two residue samples, after 8 hours of infusion as indicated by the different superscript letters.

Table 2: Comparison of the \% scavenging and phytochemical content of fruit residue

\begin{tabular}{|l|l|l|l|l|}
\hline $\begin{array}{c}\text { Sample } \\
\text { (Apple: Orange) }\end{array}$ & \multicolumn{1}{|c|}{ \% Scavenging } & $\begin{array}{c}\text { TPC } \\
\mu g G A E / m l \\
\text { sample) }\end{array}$ & $\begin{array}{c}\text { TFC }(\boldsymbol{\mu g Q E} \\
/ \mathbf{m l} \text { sample) }\end{array}$ & $\begin{array}{c}\text { Concentration of } \\
\text { Vitamin C } \\
(\boldsymbol{\mu g} / \mathbf{m l} \text { sample })\end{array}$ \\
\hline $25: 75\left(\mathrm{~T}_{1}\right)$ & $14.87 \pm 8.81^{\mathrm{a}}$ & $24.93 \pm 3.58^{\mathrm{b}}$ & $10.58 \pm 2.28^{\mathrm{d}}$ & $70.45 \pm 4.40^{\mathrm{e}}$ \\
\hline $50: 50\left(\mathrm{~T}_{2}\right)$ & $11.13 \pm 4.24^{\mathrm{a}}$ & $16.62 \pm 2.05^{\mathrm{c}}$ & $6.62 \pm 2.31^{\mathrm{d}}$ & $48.43 \pm 4.41^{\mathrm{f}}$ \\
\hline $75: 25\left(\mathrm{~T}_{3}\right)$ & $5.97 \pm 0.72^{\mathrm{a}}$ & $15.43 \pm 2.05^{\mathrm{c}}$ & $5.28 \pm 2.31^{\mathrm{d}}$ & $26.42 \pm 4.40^{\mathrm{g}}$ \\
\hline
\end{tabular}

Statistical comparisons were made using one-way ANOVA followed by Tukey-Kramer post-hoc test $(\mathrm{p}<0.05)$.

Letters in superscript indicate significance, comparing the values in the columns.

\section{Discussion}

Phenolics are secondary metabolites which are abundantly present in all plants. Phenolics include simple phenols, flavonoids, tannins, hydroxybenzoic acid, coumarines, cinnamic acid derivatives, etc. Prior to the analysis, the phenolics need to be first extracted from the source materials. Phenolics contribute to the antioxidant potential of the plants by neutralising free radicals and preventing decomposition of hydroperoxides into free radicals [19]. Free radicals are unstable atoms that have unpaired valence electron. Free radicals are produced inside the human body as a result of by-products of biochemical processes.

As per the results obtained, the longer the duration of infusion, the greater the percentage scavenging (Figure 1), total phenolic content (Figure 2) and total flavonoid content. (Figure 3). This is supported by Castiglioni et al. [20] wherein it was shown that, when some white and green teas were steeped at room temperature for different time durations $(15,30,60,120 \mathrm{~min})$, the total phenolic content, total flavonoid content and antioxidant activity of the samples increased with increasing time $(15<30<60<120 \mathrm{~min})$. Similarly, İlyasoglu and Arpa [21] reported that diffusion of antioxidants was influenced by the infusion time and concluded that longer infusion times resulted in increased antioxidant extraction up to the maximum level. According to Kyle et al. [22] the TPC of black tea beverage increased when the infusion time was increased from 3 to 10 minutes. Moreover, according to Kelebek [23], when black tea was infused in water for 3,6 and 10 minutes, the highest TPC was observed at the highest infusion time. Yang et al. [24] justified this considering that at room temperature the bioactive compounds require adequate time to diffuse from its source material into water.

As per the results obtained from this study, the greater the orange ratio in the mixture, the greater the antioxidant potential. The percentage scavenging, TPC, TFC and vitamin c content of water infused with apple: orange combinations increased in the order of 75:25 $<50: 50<25: 75$. A previous study conducted by the authors showed that apple and orange (at the eight hour of infusion) exerted $62.61 \%$ and $81.57 \%$ free radical scavenging respectively [25]. The current study has shown that apple: orange (25:75) exerted $74.45 \%$ scavenging. This is an increase from pure apple infused water $(62.62 \%)$, but a decrease in pure orange $(81.57 \%)$ infused water. Thus, it can be said that Valencia oranges possess higher antioxidant potential and total phenolic content, than Fuji apples. Herken and Guzel [26] observed that orange juice demonstrated a higher total phenolic content and total antioxidant capacity than apple juice. 
Antioxidative Potential and Phytochemical Content of Detox Water

Sánchez-Moreno et al. [27] discovered that, from all the bioactive compounds present in oranges, vitamin $\mathrm{C}$ is the bioactive compound that has possess the highest antioxidant capacity. Wang et al. [28] reported that vitamin $\mathrm{C}$ contributes to the total antioxidant capacity of a fruit. Since oranges are comprised of high amounts of vitamin C [29], it is not surprising that the antioxidant potential of Valencia orange is higher than Fuji apple. Moreover, Table 1 also proves that the higher the ratio of orange in the apple: orange mixture, the higher the vitamin $\mathrm{C}$ content.

Although the vitamin $C$ content of $T_{1}$ was significantly higher than that of $T_{3}$, the $\%$ scavenging was not (Table 1). This indicates that vitamin $\mathrm{C}$ content alone is not sufficient to significantly increase the antioxidant potential. The TPC and TFC values of trial $\mathrm{T}_{1}$ was significantly higher than that of trials $\mathrm{T}_{2}$ and $\mathrm{T}_{3}$ (Table 1). Thus, the antioxidant potential of the sample is dependent on the combination of its phytochemical (TPC, TFC and vitamin C) content.

Table 2 shows that the fruit residue of all three trials possessed low TPC, TFC and vitamin C content. The antioxidant potential of all three trials were lower than the corresponding water samples at the eight-hour of infusion. The phytochemicals present in the fruits had seeped into the water, leaving the fruit residue with low amounts of bioactive compounds and antioxidant scavenging activity.

\section{Conclusions}

This study has proven that fruit infused water (detox water) does indeed possess antioxidant properties. The longer the immersion of the fruits in water, the higher the percentage scavenging. This can be attributed to the higher total phenolic content and total flavonoid content. Prolonged immersion provided ample time for the phytochemicals to diffuse from the fruits into the water. Polyphenols, flavonoids and vitamin $\mathrm{C}$ are proven antioxidants, hence higher TPC, TFC and vitamin C content resulted in higher percentage scavenging. After 8 hours of infusion, the left-over fruit residues exhibited lower antioxidant capacity, TPC, TFC and vitamin C content than infused water, because the bioactive compounds present in the fruits had been released into the water. The study also showed that the greater the orange ratio in the mixture $\left(T_{1}\right)$, the greater the antioxidant potential, due to the higher phytochemical content. Thus, is it better to combine apples and oranges, rather than using apples alone. In conclusion, it can be said that detox water, due to the antioxidant potential has the ability to scavenge free radicals and remove toxins. Free radicals are known to be harmful to human health and are known to cause a number of diseases. Drinking fruit infused water does have beneficial properties, but in order to obtain optimal effects the fruits / fruit combination is important. Further studies can be carried out to determine the antioxidant potential of other fruits/fruit combinations; the immersion time, the fiber and mineral content and scavenging effects of other free radicals like $\mathrm{Fe}^{3+}$ ions (FRAP assay) and peroxidase activity (ABTS assay).

\section{Declarations}

\subsection{Study Limitations}

Maximum immersion time was limited to 8 hours as laboratory facilities were unavailable after 5:00pm.

\subsection{Acknowledgements}

Nilai University, Negeri Sembilan, Malaysia.

\subsection{Funding Source}

Funding for the study was obtained from the Final Year Research course fees.

\subsection{Competing Interests}

Authors declare no conflict of interest. 


\section{How to Cite this Article:}

G. P. Ariyawansa and R. Ramanathan, “Antioxidative Potential and Phytochemical Content of Detox Water”, Adv. J. Grad. Res., vol. 10, no. 1, pp. 41-50, Jul. 2021. https://doi.org/10.21467/ajgr.10.1.41-50

\section{References}

[1] Healthshots, "We asked nutritionists if detox water really works or is it just a fad. This is what they have to say," August, 2020. Access online on 11 June 2021 at https://www.healthshots.com/healthy-eating/nutrition/we-asked-nutritionists-if-detox-water-reallyworks-or-is-it-just-a-fad-this-is-what-they-have-to-say/

[2] Healthline, "What Is the Average (and Ideal) Percentage of Water in Your Body?" July, 2019. Accesss online on 11 June 2021 at https://www.healthline.com/health/body-water-percentage

[3] 1and1life, "Top 10 Water Benefits You Should Know," March, 2020. Access online on 11 June 2021 at https://www.1and1life.com/blog/water-benefits/

[4] A. Bellavia, S.C. Larsson, M. Bottai, A. Wolk and N. Orsini, "Fruit and vegetable consumption and all-cause mortality: A doseresponse analysis," The American Journal of Clinical Nutrition, vol 1, no. 98 (2), pp. 454-459, Aug. 2013. https://doi.org/10.3945/ajcn.112.056119

[5] T.S. Conner, K.L. Brookie, A.C. Carr, L.A. Mainvil and M.C.M. Vissers, "Let them eat fruit! The effect of fruit and vegetable consumption on psychological well-being in young adults: A randomized controlled trial," PLoS One, vol 12, no 2, Feb. 2017, e0171206. https://doi.org/10.1371/journal.pone.0171206

[6] O. Oyebode, V. Gordon-Dseagu, A. Walker and J.S. Mindell, "Fruit and vegetable consumption and all-cause, cancer and CVD mortality: Analysis of Health Survey for England data," Journal of Epidemiology and Community Health, vol 68, no. 9, pp. 856-862, Sept. 2014. https://doi.org/10.1136/jech-2013-203500

[7] B.J. Rolls, J.A. Ello-Martin and B.C. Tohill BC, "What can intervention studies tell us about the relationship between fruit and vegetable consumption and weight management?” Nutrition Review, vol 62, no. 1, pp. 1-17, Jan. 2004. https://doi.org/10.1111/j.17534887.2004.tb00001.x

[8] K. He, F.B. Hu, G.A. Colditz, J.E. Manson, W.C. Willett and S. Liu, "Changes in intake of fruits and vegetables in relation to risk of obesity and weight gain among middle-aged women," Int J Obes Relat Metab Disord, vol. 28, no. 12, pp1569-1574, Dec. 2004. https://doi.org/10.1038/sj.ijo.0802795

[9] R. H. Liu,(2013). "Health-Promoting Components of Fruits and Vegetables in the Diet," Advances in Nutrition, vol. 4, no. 3, pp. 384S-392S, May 2013. https://doi.org/10.3945/an.112.003517

[10] C. Kaur and H.C. Kapoor, "Antioxidants in fruits and vegetables - the millennium's health," Food Science and Technology, vol. 36, no. 7, pp. 703-725, July 2008. https://doi.org/10.1111/j.1365-2621.2001.00513.x

[11] K. Thiagarajah, M. Ong, L. Teh and H. Lye, "Plants infused water as preferred healthy drinks," Bottled and Packaged Water, pp. $367-$ 402, Nov. 2019,

[12] N. Theola, "The stability of vitamin c and antioxidants activity on strawberry infused water use glass and plastic packaging on 0-12 hours of immersion", Semararang, Indonesia: Universitas Katolik Soegijapranata, Faculty of Agricultural Technology., 2018

[13] Nutritionstripped, "How to make infused water | Simply infused water recipes," July, 2020. Access online 26July 2019 at https://nutritionstripped.com/simply-infused-water/

[14] K. Sridhar and A. Charles, "In vitro antioxidant activity of Kyoho grape extracts in DPPH and ABTS assays: Estimation methods for EC50 using advanced statistical programs," Food Chemistry, vol. 275, pp. 41-49, March 2019. https://doi.org/10.1016/j.foodchem.2018.09.040

[15] H. Arruda, G. Pereira and G. Pastore, "Optimization of extraction parameters of total phenolics from Annona crassiflora Mart. (Araticum) fruits using response surface methodology," Food Analytical Methods, vol. 10, no.1, pp. 100-110,2017. https://doi.org/10.1007/s12161-016-0554-y

[16] S. Kamtekar, V. Keer and V. Patil, "Estimation of phenolic content, flavonoid content, antioxidant and alpha amylase inhibitory activity of marketed polyherbal formulation,” Journal of Applied Pharmaceutical Science, vol. 9, no.9 pp. 61-65, Jan 2014. https://doi.org/10.7324/JAPS.2014.40911

[17] Canterbury University, "Determination of vitamin c concentration by titration (Redox titration using iodine solution," Accessed online at https://www.canterbury.ac.nz/media/documents/science-outreach/vitaminc_iodine.pdf

[18] C. Sun, Z. Wu, Z. Wang and H. Zhang, "Effect of ethanol/water solvents on phenolic profiles and antioxidant properties of Beijing propolis extracts," Evidence-Based Complementary and Alternative Medicine, vol. 2015, pp. 1-9, July 2015. https://doi.org/10.1155/2015/595393

[19] S. Chanda and R. Dave, "In vitro models for antioxidant activity evaluation and some medicinal plants possessing antioxidant properties: An overview," African Journal of Microbiology Research, vol. 3, no. 13, pp. 981-996, Dec 2009.

[20] S. Castiglioni, E. Damiani, P. Astolfi and P. Carloni, "Influence of steeping conditions (time, temperature, and particle size) on antioxidant properties and sensory attributes of some white and green teas," International Journal of Food Sciences and Nutrition, vol. 66, no. 5, pp. 491-497. May 2015. https://doi.org/10.3109/09637486.2015.1042842

[21] H. İlyasoglu and T. Arpa, "Effect of brewing conditions on antioxidant properties of rosehip tea beverage: Study by response surface methodology," Journal of Food Science and Technology, vol, 54, no. 11, pp. 3737-3743, Oct. 2017. https://doi.org/10.1007/s13197017-2794-2

[22] J, Kyle, P. Morrice, G. McNeill and G. Duthie, "Effects of infusion time and addition of milk on content and absorption of polyphenols from black tea," Journal of Agricultural and Food Chemistry, vol. 55, no. 12, pp. 4889-4894, May 2007, doi.org/10.1021/jf070351y

[23] H. Kelebek, "LC-DAD-ESI-MS/MS characterization of phenolic constituents in Turkish black tea: Effect of infusion time and temperature," Food Chemistry, vol. 204, pp. 227-238, Aug. 2016. https://doi.org/10.1016/j.foodchem.2016.02.132 
Antioxidative Potential and Phytochemical Content of Detox Water

[24] D. Yang, L. Hwang and J. Lin, "Effects of different steeping methods and storage on caffeine, catechins and gallic acid in bag tea infusions," Journal of Chromatography A, vol. 1156 no. 1-2, pp. 312-320, July 2007. https://doi.org/10.1016/j.chroma.2006.11.088

[25] Ariyawansa and Ramanathan, "Antioxidant properties of fruit infused water", Undergraduate Research Conference 2021, Nilai, Negeri Sembilan, Conference paper.

[26] E. Herken and S. Guzel, "Total antioxidant capacity and total phenol contents of selected commercial fruit juices in Turkey," International Journal of Food Properties, vol. 13, no. 6, pp. 1373-1379, May 2007. https://doi.org/10.1080/10942912.2010.499039

[27] C. Sánchez-Moreno, L. Plaza, B. de Ancos and M. P. Cano, "Quantitative bioactive compounds assessment and their relative contribution to the antioxidant capacity of commercial orange juices," Journal of the Science of Food and Agriculture, vol. 83, no. 5, pp. 430-439, March 2003. https://doi.org/10.1002/jsfa.1392

[28] H. Wang, G. Cao and R. Prior, "Total antioxidant capacity of fruits," Journal of Agricultural and Food Chemistry, vol. 44, no. (3), pp. 701-705, March 1996. https://doi.org/10.1021/j950579y

[29] P.C. Njoku, A.A. Ayuk, and C.V. Okoye, "Temperature Effects on Vitamin C Content in Citrus Fruit," Pakistan Journal of Nutrition, vol 10, no. 12, pp. 1168-1169, 2011. https://doi.org/10.3923/pjn.2011.1168.1169

Publish your books with AIJR publisher-

- $\quad$ Publish with ISBN and DOI.

- $\quad$ Publish Thesis/Dissertation as Monograph.

- Publish Book Monograph.

- $\quad$ Publish Edited Volume/ Book.

- $\quad$ Publish Conference Proceedings

- Retain full copyright of your books.

Submit your manuscript at books.aijr.org
Publish your research article in AIJR journals-

- Online Submission and Tracking

- Peer-Reviewed

- Rapid decision

- Immediate Publication after acceptance

- Articles freely available online

- Retain full copyright of your article.

Submit your article at journals.aijr.org 